\title{
Communication techniques. A Case Study: Negotiation in a Bank
}

\author{
Sorina DÂRJAN, Sebastian-Călin VAC \\ University of Agricultural Sciences and Veterinary Medicine of Cluj Napoca, 3-5 Calea Mănăștur, 400372 \\ Cluj-Napoca, Romania \\ *corresponding author, e-mail: calin.vac@usamvcluj.ro
}

Bulletin UASVM series Agriculture 73(1)/2016

Print ISSN 1843-5246; Electronic ISSN 1843-5386

DOI 10.15835/buasvmcn-agr: 12022

\begin{abstract}
This paper is a case report, which analyzes in terms of quality the negotiation process from two particular standpoints: the banking and project management areas.

Although the domain of the legal persons credits analysis, and that developing project management are relatively similar, since both treat the analysis, development and implementation of projects for business, yet each of these fields has their own peculiarities, determined primarily by the fact that: while, as a credit analyst, you are the bank "consultant" (you represent the financing party) and you promote its interests, as a project manager you are the the customer's "consultant" (meaning the legal entity beneficiary of funding). Therefore, although the areas of activity are related, the manner of reporting differs systematically: top-bottom or bottom-up. The research methods are based on the analysis of the instances encountered in practice, the study taking into account over two hundred credit analysis and over thirty written and/or implemented projects. Our study shows that depending on which side of the negotiating table the subject is located (the positions of the financier or financed), then the practice of projects implementing (in both cases) demonstrates that all the situations presented are real, possible, often encountered and the best tactics in solving them is prevention, avoiding to reach sensitive situations, completed by a professional, honest and cooperative attitude maintained throughout the entire project implementation.
\end{abstract}

Keywords: communication, negotiation technics, project management, credit analysis

\section{INTRODUCTION}

Communication is an open system, influenced by many factors. Altman et al. (1985) established the following major barriers to effective communication: emotional blockages, different communicative repertoire, the transmitter's failure to adequately express himself, the features of either communicator etc.

While communication is a process undertaken on a daily basis, the conflict is an everyday ingredient of our experience of life. One can easily enter a conflict, but can leave with difficulty. Generally speaking, people are increasingly less prepared to cope with the demographic avalanche of recent years, and this phenomenon leads to of life-long contact with many different people in order to complete the set-out activities. This aspect involves the strategic development of effective communication and, in the mean time, leads to positive solving conflicts that are inevitable (de Vito, 1988). Moreover, the conflict can not be avoided, every individual's involvement in resolving the conflict results in an efficiency of the relationsip's quality. A lack of conflict in the communicaitonl process is potentially inauthentic, which does not accomplish the expected attributions, those of efficiency. This aspect requires a solution that can be staggered in three important points:

- The identification of the problem, with the avenues from which the conflict can ignite;

- The conflict solving with a focus on the sociocommunicational component of the phenomenon;

- The valuation of the acquisitions that follow the conflict. 
Conflicts themselves often arise from, "a lack of understanding about different needs" but the resolutions usually require feelings of security and respect (Segal \& Smith, 2014).

Conflict resolution is seen as the management of differences in a manner that is constructive and cooperative, and yields outcomes that are mutually satisfactory and have a long-term commitment from the parties (Fisher, 2015).

In this respect, the knowledge of the negotiating tactics can support the avoiding of the negative effects that they may require in order to consolidate a positive climate based on mutual confidence and motivation (Petrescu, 2007).

In practice, six negotiation stages may be identified:

- Negotiation preparation, with three sub-phases: setting the goals of the negotiation, the evaluation of the other party case, assessing strengths and weaknesses. Regarding the setting of the goals in negotiation Hiltrop and Udall (1995) set out three categories of objectives: a "first line" objective, with the best achievable outcome; a "last line" objective, less optimistic but with acceptable results; a target objective what is expected to be effectively achieved;

- The development of a strategy;

- The initiation of the negotiation - setting out the subjects to be discussed;

- The clarification of the positions of both parts, with three components - obtaining information, testing arguments, usage of the time interval, and postponings;

- The negotiations with other three stages obtaining concessions, overcoming bottlenecks, trying to settle an agreement;

- The finalization of the negotiations (where we focus on producing an agreement and ensure its application). Equally important is the positive atmosphere when concluding the negotiation. In this case, a win-win strategy should be applied.

This article aims to capture the main aspects of the"consultant" in two situations, from the personal experiences of one of the author, and analyze the main techniques of communication and negotiation tactics applicable in specialty practice.

\section{MATERIALS AND METHODS}

The case study is focused on a 15-year communication experience within the development of loans policy in Transilvania Bank, Cluj-Napoca Branch, Romania, on the one hand, and on the management experience in the field of the project management, both in obtaining bank financing (refundable) and in developing and implementing projects with grant funding (national funds, European structural funds, other funds).

The research methods are based on the analysis of situations encountered in practice. In this study, over two hundred credit analyses are considered, and over thirty projects applications and/or implemented projects (Vac, 2015).

\section{RESULTS AND DISCUSSIONS}

In order to highlight the business negotiation tactics used so far, it is necessary to pann through the stages of professional development that deemed negotiations as necessary. They may be more consistent or less consistent, depending on the context in wich they are used: in the field of banking and project management respectively.

From the perspective of the loan analyst for legal persons, within Transilvania Bank, Cluj-Napoca Branch, Romania, the negotiation component was used both in the analysis phase of the more than 400 cases of lending, especially in the development phase for the promotion and approval of more than 250 credit files. The following tactics were used the most often:

- "Warming (Adaptation)", followed by "Small steps", "Caution approach"- the progressive data entry was aimed at, up to the level at which all the important information needed for analysis were obtained;

- "Listerning", "Interest" - against a good and interested listener, customers often have the opening to present their business ideas for which they are seeking funding;

- "Isn't it ..." - there were plenty of instances where some information were derived from document analysis (checking documents, analytical documents of certain accounts, etc) and were confirmed by the client using this technique;

- "The use of condoitionalities","Yes, but...", "Limit", "Multiple solutions", "Batch", “Options limitation” - are the techniques used in the stage of the negociation of the loan granting conditions: settlement of interest threshold, commission level, guarantees structure, reimbursement conditions, etc; 
- "No"- unfortunately, the use of this technique is absolutely necessary in situations when some files cannot be be funded, because they are not compatible with the bank policy, with standard credit conditions, creditation fileds, or just with the economic and financial situation of the soliciter;

- "I want, but the others don't", "Lack of authority"or "Indifference"- it needs to be used when, despite the firm opposition of the analyst, the customer insists on obtaining a loan request;

-"Mediation"- although credit analysts are typically economists and do not have a concrete specialty in the field, often, the mediation is used during analysis, in order to settle various conflicts that arise between the management staff of the applicant company (directors, executives, associates etc.) and different divisions within the company (usually Accounting and Logistics), whose declared/required activities do not match the realities edified by accounting records, or economic and financial indicators calculated based on accounting documents submitted for analysis;

- "Empathy", "Decompression", "Humor" - they are absolutely welcome during the communication with the customer, both to gain their trust, and to alleviate various situations and to retain them in relation with the bank and its team of analysts;

- "Time investment" - time is money for everyone, therefore a correct optimization of the time period allocated to each customer will generate an optimization of the planned activity of each analyst, and optimization of the income of the bank;

- "Why?", "Why not", "Questions" - there are probably the most used negotiating tactics with customers, in the spirit of understanding their need for business development through financing of certain commercial activities that they consider as necessary, but in the spirit of understanding the company's strategy, and also objectives and policies of the company.

Beyond these direct negotiation tactics used by analysts, during negotiations with customers it is necessary that the analyst be prepared to counter negotiation tactics advanced by the clients, such as:

- "Messenger", "Lack of authority", "Unreal authority", "The ignorant", "Answer avoiding"
- techniques of passing responsibility, hoping that the analyst will "close his eyes" or he will consider a particular detail less important or relevant. In these situations, the analyst uses tactics such as "No", "Why?", "Why not?", "Questions," "I want, but others do not", etc.

- "Mistification", "Deliberate errors", "Incorrect summarization", "Diversion", "Bribing", "Threat", "Malevolent manipulation" - in these situations, most often the tactics of response from the analyst "Interlocutor blaming the interlocutor, primarily due to lack of confidence in the managerial character and prevention of situations that could be damaging to the bank;

- "Exagerate politeness", "Friendship and honestity", "Prommising", "Mill rumbling" leads analyst to become thoughtful, cautious and to insist with "Questions", "The investment of time", "Do not be willing to negotiate," "Yes, but ..." "No," etc., in order to clarify the required details, or conversely, to build a polite refusal.

From the perspective of the project manager, the communicational tools specific to negotiation have some particularities, whatever contractor may be, meaning private institution or public institution.

The first negotiation tactics to be used are those leading to the approval of the financing strategy, the team's formation analysis, project development and management approach, required in each project. In this sense, the tactics used are:

- "Interest" - to atract both management and new team members;

-"Reciprocity" - to include both management and team members;

-"If..., then..." - for assuming indicators of achievement and results, but also to motivate the team;

- "Cautious approach" - in order to start with right step and avoid unnecessary work;

- " Empathy ", " Decompression ", " Humor " absolutely necessary within the team, for installation of a relaxed atmosphere; to establish a professional but cheerful environment, involved but relaxed, appropriate for a healthy development of the project.

By contrast, the greatest challenges in terms of business negotiation occurring during the implementation of a project, both in the stage of contracting of the partners (providers), but especially in the stage of execution of contracts. 
Thus, these tactics steps necessary to successful finalizations of the projects are:

- "The use of conditionalities", "Foreseen", "Mobile exigencies", "Questions", "Listening", "Question to the question" - in the stage of contracting the providers, who must be well selected and particularly well motivated from the beginning of the collaboration in the direction of supplying competent and responsible contractual obligations;

- "Generosity", "Reciprocity", "Empathy", "Friendship and hospitality", "Decompression”, "Humor" - each relationship should start from the assumption of full cooperation and availability of the financing beneficiary, in a relaxed, but professional and responsible atmosphere;

- "Interest ", "Obstacle", "Small steps", "Balance", "Listening", "Questions", "Why?”, "Why not?" throughout the period of the contract execution, in a peaceful and favorable atmosphere, with the aim of the completion of project implementation and achievement of its outputs and outcomes;

- "The use of coercition", "The ultimatum," "The frontal attack", "Hostage", "Do not be willing to negotiate," "I want to, but others do not", "Mediation", "Demolition", "Blaming the interlocutor", "Defeating opponent with his weapons" "Paraphrase", "Detective Colombo" whenever registers slippages from the natural development and implementation of the contracts, or whenever providers try to use or to impose tactics like "the blackmail", "Dead cat", "Bazaar", "The messenger", "The lack of authority", "The irreal authority", "Indifference, "Postponing", "Fraud ", "Deliberate errors", "Diversion", "The false offer", "Bribing", "Avoiding responses", "Silence,,"'The psychological war", "The threat","'The malevolent manipulation".

\section{CONCLUSIONS}

In this case report we demonstrated the applicability of different negotiation styles depending on the context in which they are used. The literature identifies a wide range of techniques, tactics and negotiation tools, but the way they are applied is crucial to the success or failure of the communication process. It is important, whatever negotiation side you occupy, to adopt a performant approach in communicational terms, with the respect of the basic principles of both the communication and negotiation.

If you stand by the funder side, you benefit from a position of strength in negotiations, which may be imposed on a number of situations, and communication and negotiation are stimulated by the need to make important investments, from quantitative point of view, with the aim of making profit.

However, if you stand by the beneficiary financing side, seeking solutions for optimum use of funding attracted as consequence of the negotiation, in this case, it will be based on a real need and having permanent market pressures (return of investment), but also of the judicious use of the obtained financing.

Unfortunately, the practice of project implementation demonstrates that all statements above are true, possible, often encountered and the best tactics for their mitigation is prevention, avoiding to reach sensitive instances, completed with maintaining an honest, professional and cooperative attitude throughout the implementation period.

\section{REFERENCES}

1. Altman MV, Goetscher J, Seibert JH (1993). Adecade of organizational communication research: Journal articles 1980-1991, Communication Yearbook.

2. Fisher RJ (2015), Conflict and Conflict Resolution, Social Psychology of, International Encyclopedia of the Social \& Behavioral Sciences, 2nd edition, Volume 4

3. Hiltrop JM, Udall S (1995). The essence of negotiation, London: Prentice Hall.

4. Petrescu DC (2007). Negocieri in afaceri (vol. II), Editura Fundatiei pentru Studii Europene, Cluj-Napoca.

5. Segal J, Smith, M (2014). Conflict Resolution Skills: Building the Skills That Can Turn Conflicts into Opportunities.

6. Vac C (2015). http://www.usamvcluj.ro/files/ comisie/2012/vac3.pdf.

7. deVito J (1988). Human Communication: The basic Course, Harper \& Row Press. 